\title{
A chloride channel in rat and human axons
}

\author{
M. Strupp and P. Grafe \\ Department of Physiology, University of Munich, Munich (F.R.G.)
}

(Received 2 August 1991; Revised version received 6 September 1991; Accepted 9 September 1991)

Key words: Axon; Myelinated fiber; Patch clamp; Single chloride channel; Background conductance; Rat; Human

\begin{abstract}
Current recordings from single chloride channels were obtained from excised and cell-attached patches of rat and human axons. In rat axons the channels showed an outwardly rectifying current-voltage relationship with a slope conductance of $33 \mathrm{pS}$ at negative membrane potentials and $65 \mathrm{pS}$ at positive potentials (symmetrical $150 \mathrm{mM} \mathrm{CsCl})$. They were measurably permeable for cations $\left(\boldsymbol{P}_{\mathrm{Na}} / \boldsymbol{P}_{\mathrm{Cs}} / \boldsymbol{P}_{\mathrm{Cl}}=0.1 / 0.2 / 1\right)$. Channel currents were independent of cytoplasmatic calcium concentration. Inactivation was not observed and gating was weakly voltage dependent. $\mathrm{Cl}$ - channels in human axons showed similar gating behavior but had a lower conductance.
\end{abstract}

Enzymatic dissociation and demyelination of myelinated axons enables single channel current recordings from the nodal and paranodal region [11]. Using this method one type of $\mathrm{Na}^{+}$channel and several types of $\mathrm{K}^{+}$channel have been described [11, 12]. Another axonal conductance known from macroscopic current recordings in squid axons [10], non-myelinated rat axons [3] and myelinated rabbit axons [4] is $\mathrm{Cl}^{-}$dependent. To our knowledge, single chloride channels have not been described previously in mammalian axons.

A certain type of $\mathrm{Cl}^{-}$channel with distinctive properties has been found in a variety of other cells, e.g. cultured hippocampal neurons [5, 16], Drosophila neurons [18], crustacean axons [13] or tracheal epithelial cells [17]. This channel has an intermediate conductance (10$100 \mathrm{pS}$ ), is significantly permeable to cations (permeability ratio in the range of $0.1-0.35$ ) and shows weak voltage-dependent gating. This type of channel has been designated as a 'background' $\mathrm{Cl}^{-}$channel by Franciolini and Petris [6]. $\mathrm{A} \mathrm{Cl}^{-}$channel with similar electrophysiological characteristics was observed in about 5\% of all gigaseal recordings from axonal patches obtained in the present study.

Experiments were performed on ventral rat spinal roots and specimens of human sural nerves. Male Wistar rats $(250-350 \mathrm{~g})$ were anaesthetized with urethane $(1.25$ $\mathrm{mg} / \mathrm{kg}$, i.p.). After laminectomy $5-10$ ventral roots were removed and transferred into a culture dish. Enzymatic

Correspondence: $\mathrm{M}$. Strupp, Department of Physiology, University of Munich, Pettenkoferstr. 12, D-8000 Munich 2, F.R.G. dissociation and paranodal demyelination were performed in two steps according to the procedures described by Jonas and coworkers [11] with some modifications. Spinal roots were first treated at $37^{\circ} \mathrm{C}$ with collagenase ('Worthington' type CLS II, $135 \mathrm{U} / \mathrm{mg}$; Biochrom, Berlin; $3 \mathrm{mg} / \mathrm{ml}$, diluted in normal Ringer solution) for $80 \mathrm{~min}$ and subsequently incubated for $30 \mathrm{~min}$ in protease (type XXIV; $8 \mathrm{U} / \mathrm{mg}$; Sigma, Deisenhofen, F.R.G.; $1 \mathrm{mg} / \mathrm{ml}$, diluted in calcium-free Ringer solution). After this procedure the spinal roots were cut into $3 \mathrm{~mm}$ segments and single fibers were dissociated by gentle shaking. Finally, they were transferred into dishes precoated with poly-L-lysine $(1 \mathrm{mg} / \mathrm{ml}$; Sigma). Sural nerves were obtained from patients who required nerve biopsy for clinical diagnosis at the Department of Neurology, Technical University of Munich. Human nerves were treated as described above. However, in the first step, collagenase plus protease (type X, $62 \mathrm{U} / \mathrm{mg}$; Sigma; $0.03 \mathrm{mg} / \mathrm{ml}$ ) were used for $120 \mathrm{~min}$.

Single channel recordings were performed in solutions of the following composition (in $\mathrm{mM}$ ): (a) ' $\mathrm{CsCl}$ ': 150 $\mathrm{CsCl}, 0.464 \mathrm{CaCl}_{2}, 1.18 \mathrm{MgCl}_{2}, 1$ EGTA, 10 HEPES; (b) ' $\mathrm{NaCl}$ ': $150 \mathrm{NaCl}, 0.464 \mathrm{CaCl}_{2}, 1.18 \mathrm{MgCl}_{2}, 1$ EGTA, 10 HEPES and (c) 'NMDG-Cl': $150 \mathrm{~N}$-methyl-D-glucamine chloride, $0.464 \mathrm{CaCl}_{2}, 1.18 \mathrm{MgCl}_{2}, 1$ EGTA, 10 HEPES; pH 7.4 (adjusted with $\mathrm{NaOH}$ ). Wherever solutions did not have one of the compositions given above, it is explicitly mentioned in the text. Experiments were done at room temperature, approximately $22^{\circ} \mathrm{C}$. Recordings were performed by standard patch-clamp technique [8]. Patch pipettes were drawn (DMZ puller; Zeitz, Augsburg, F.R.G.) from borosilicate glass tubings 
(GC $150 \mathrm{TF}$ - 10, Clark Electromedical Instruments, Pangbourne, U.K.), coated with Sylgard and firepolished immediately before the experiment. The pipettes had a resistance of 10-20 $\mathrm{M} \Omega(150 \mathrm{mM} \mathrm{CsCl})$. Recordings were made with an Axopatch 200 amplifier (Axon Instruments, Foster City, CA, U.S.A.). The cur-
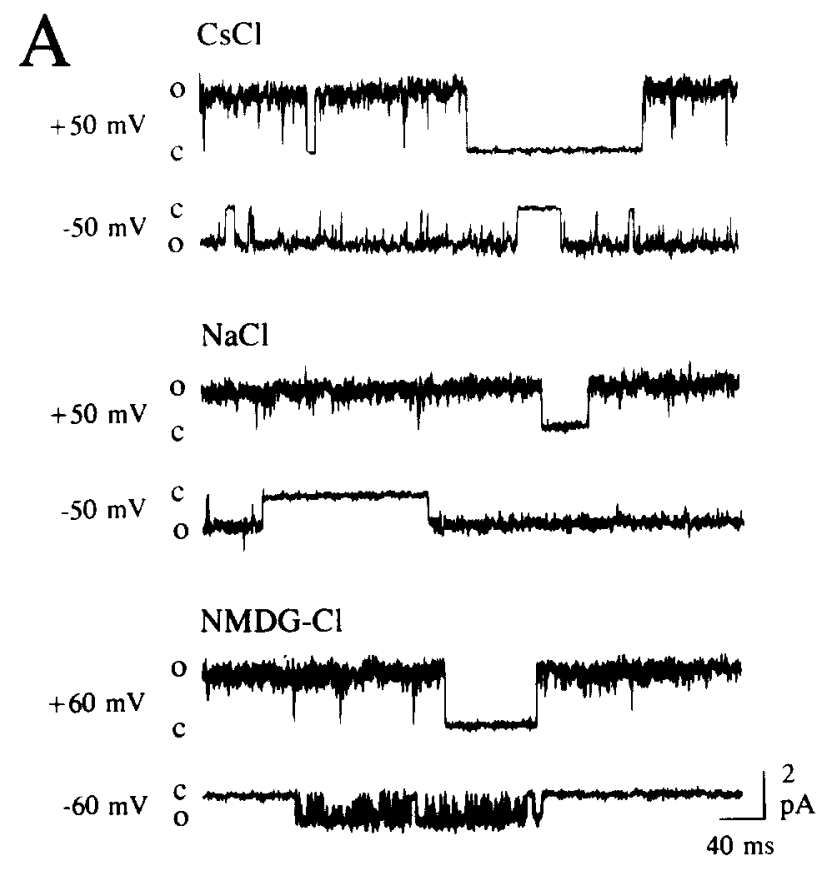

B

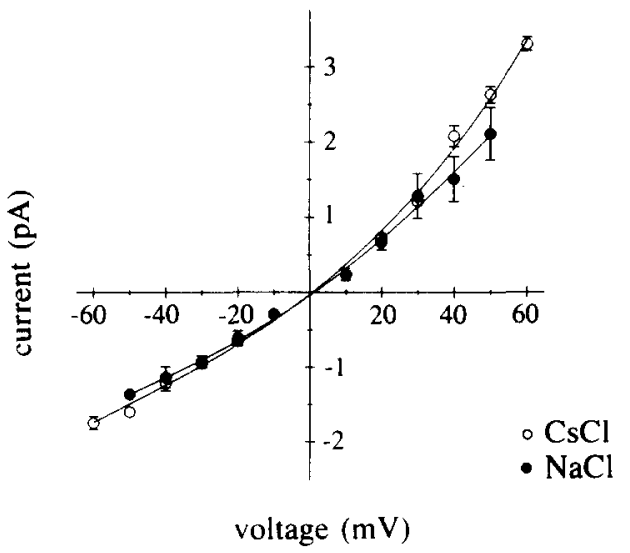

Fig. 1. A: single channel recordings of the $\mathrm{Cl}^{-}$channel from rat axons in symmetrical $150 \mathrm{mM} \mathrm{CsCl}$ solution (excised, outside-out configuration), in symmetrical $150 \mathrm{mM} \mathrm{NaCl}$ solution (excised, inside-out configuration) and in symmetrical $150 \mathrm{mM} \mathrm{N}$-methyl-D-glucamine $\mathrm{Cl}^{-}$ (NMDG-Cl) solution (cell-attached configuration). Voltages given are membrane potentials. Closed and open states are indicated by $\mathrm{c}$ and $o$, respectively. B: single channel current-voltage relationship of the $\mathrm{Cl}^{-}$channel from rat spinal roots. Illustrated data are averaged (mean \pm S.D.) from 4 recordings in symmetrical $\mathrm{CsCl}(\mathrm{O})$ and from 4 recordings in symmetrical $\mathrm{NaCl}(\odot)$ and each current value is the average of 5 amplitude measurements from these 4 channels. In $\mathrm{CsCl}$ solutions the slope conductance ranged from $33 \pm 3 \mathrm{pS}$ (mean \pm S.D.) at negative membrane potentials to $65 \pm 2 \mathrm{pS}$ at positive membrane potentials with a reversal potential close to $0 \mathrm{mV}$. The slope conductance in $\mathrm{NaCl}$ was $24 \pm 1 \mathrm{pS}$ for inward currents and $46 \pm 6 \mathrm{pS}$ for outward currents. The curves were fitted by a polynomial function. rent signals were low pass filtered at $1.2 \mathrm{kHz}$ and digitized at a sampling rate of $10 \mathrm{kHz}$. They were stored and analyzed using a Tandon 386/33 computer and pClamp 5.5 software (Axon Instruments). Voltages given indicate membrane potential.

The recordings illustrated in Fig. 1A were obtained from patches of the (presumed) paranodal area in different symmetrical solutions: $\mathrm{CsCl}, \mathrm{NaCl}$ and NMDG-Cl. Channel activity was observed in the cell-attached as well as in the excised configuration. Current-voltage relationships shown in Fig. IB reveal an outward rectification, which is typical for most of the non-transmitter gated $\mathrm{Cl}^{-}$channels $[6,7]$. In $150 \mathrm{mM} \mathrm{CsCl}$ solutions slope conductance ranged from $33 \pm 3 \mathrm{pS}$ (mean \pm S.D., $n=4$ ) at negative membrane potentials ( -50 to -20 $\mathrm{mV})$ to $65 \pm 2 \mathrm{pS}$ at positive membrane potentials $(+20$ to $+50 \mathrm{mV}$ ) with a reversal potential close to $0 \mathrm{mV}$. In symmetrical $\mathrm{NaCl}$ solutions the slope conductance was $24 \pm 1 \mathrm{pS}(n=4)$ for inward currents and $46 \pm 6 \mathrm{pS}$ for outward currents. Channel activity was also found in solutions with NMDG-Cl.

We have observed different patterns of gating. Single channel gating was mainly characterized by long lasting open and short closed states (see Fig. 1A) and no in-activation. In $<10 \%$ the channel spontaneously shifted to a rapid 'flickering' behavior during the recordings. In addition, long lasting closed states were found. Similar gating behavior was described for a $\mathrm{Cl}^{-}$channel from lobster walking leg nerves [13]. Open probability $\left(P_{\mathrm{o}}\right)$ was calculated from the all point amplitude histogram of patches with only one channel. For each voltage a minimal time of $15 \mathrm{~s}$ was analyzed. In most recordings $P_{\mathrm{o}}$ was high $\left(0.80-0.95\right.$; not shown). $P_{\text {o }}$ showed a weak voltage dependence; in some patches it increased with depolarization. Since a Ca-dependent $\mathrm{Cl}^{-}$conductance has been reported, e.g. in cultured mouse spinal neurones [14], we tested the effects of different $\mathrm{Ca}$ concentrations (ranged from $2.2 \mathrm{mM}$ to nominally Ca-free solutions). In our experiments single channel currents were not influenced by cytoplasmatic calcium (not shown).

Further experiments were performed in asymmetrical solutions to estimate permeability ratios for cations versus $\mathrm{Cl}^{-}$. Therefore, the shift of the reversal potential of the current-voltage relationship was measured. By means of the Goldman-Hodgkin-Katz equation (using ion activities as given by Robinson and Stokes [15]) permeability ratios were calculated after subtraction of junction potentials. In all experiments, unilateral changes in the $\mathrm{Cl}^{-}$concentration shifted the reversal potential in the direction expected for $\mathrm{a} \mathrm{Cl}^{-}$channel (see Fig. 2). In one set of experiments the bath contained 150 $\mathrm{mM} \mathrm{NaCl}$ and the pipette was filled with $75 \mathrm{mM} \mathrm{NaCl}$ ( $50 \%$ of $\mathrm{NaCl}$ was replaced isoosmotically by sucrose). 


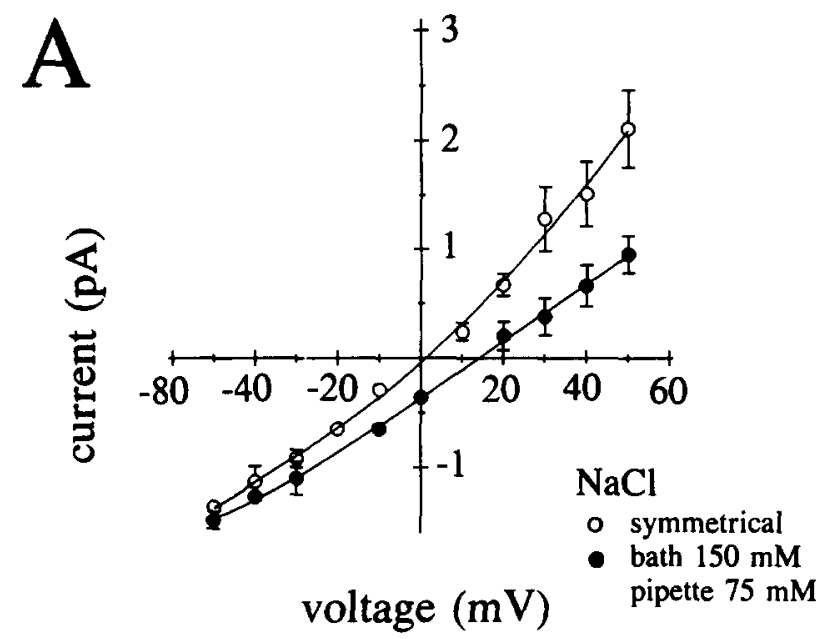

B

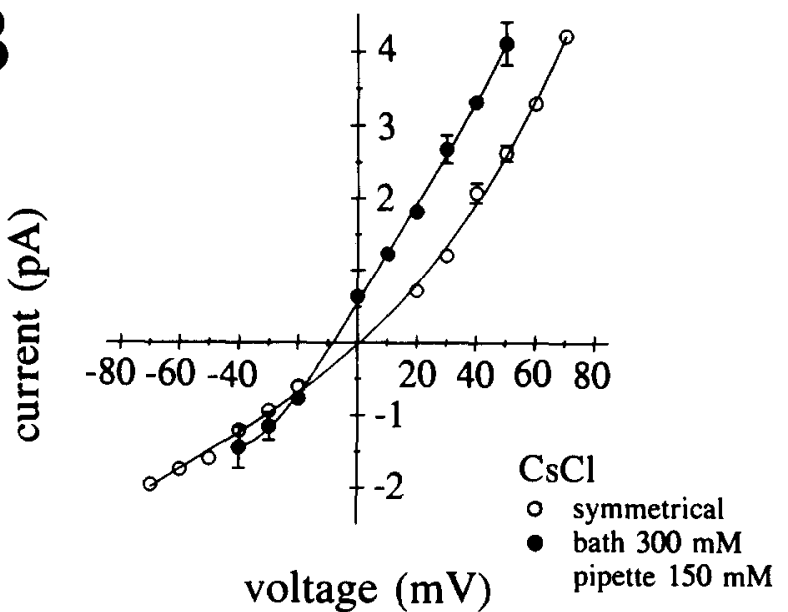

Fig. 2. Single channel current-voltage relationship of the $\mathrm{Cl}^{-}$channel from rat axons in symmetrical and asymmetrical solutions. Illustrated data are averaged (mean \pm S.D.) and determined as described in Fig. 1. A: data from recordings in the inside-out configuration. Unfilled circles $(O)$ show the current-voltage relationship under conditions of symmetrical $\mathrm{NaCl}(n=4)$. The reversal potential was $+1.5 \mathrm{mV}$. Filled circles (@) represent data $(n=4)$ with $150 \mathrm{mM} \mathrm{NaCl}$ in the bath and $75 \mathrm{mM} \mathrm{NaCl}$ in the patch pipette $(50 \%$ of $\mathrm{NaCl}$ substituted isoomotically by sucrose). Note the reversal potential of $+14 \mathrm{mV}$, i.e. there was a shift of $+12.5 \mathrm{mV}$. B: data from recordings in the outside-out configuration. Unfilled circles $(O)$ show data under conditions of symmetrical $150 \mathrm{mM} \mathrm{CsCl}(n=4)$. The reversal potential was $+0.5 \mathrm{mV}$. Filled circles (-) show the current-voltage relationship with $150 \mathrm{mM} \mathrm{CsCl}$ in the pipette and $300 \mathrm{mM} \mathrm{CsCl}$ in the bath $(n=3)$. The reversal potential was $-9.5 \mathrm{mV}$, i.e. the shift was $-10 \mathrm{mV}$. For calculation of permeability ratios see text. The curves were fitted by a polynomial function.

As illustrated in Fig. 2A, this caused a shift of the reversal potential of $\approx+12.5 \mathrm{mV}$, i.e. the permeabitity ratio $P_{\mathrm{Na}} / P_{\mathrm{Cl}}$ was $\approx 0.1$. In a second set of experiments performed in the outside-out configuration the pipette contained $150 \mathrm{mM} \mathrm{CsCl}$ solution and the bath solution consisted of $300 \mathrm{mM} \mathrm{CsCl}$ (Fig. 2B). The shift of the reversal potential of $\approx-10 \mathrm{mV}$ measured under these conditions revealed a permeability ratio of $P_{\mathrm{Cs}} / P_{\mathrm{Cl}} \approx 0.2$. Experiments with potassium were not performed because there is a high density of $\mathrm{K}^{+}$channels in axons, which makes it difficult to identify $\mathrm{Cl}^{-}$channels. The observed significant permeability for cations was not unexpected, because in serveral tissues $\mathrm{Cl}^{-}$channels with such characteristics have been described $[2,5,17]$.

Fig. 3A shows single channel recordings from a human axon performed in symmetrical $\mathrm{NaCl}$. In human axons, we also observed a $\mathrm{Cl}^{-}$channel, which, however, had a lower conductance. The current-voltage relationship revealed outward rectification (see Fig. 3B). Slope conductance was $14 \pm 1 \mathrm{pS}$ at negative membrane potentials $(-50$ to $-20 \mathrm{mV})$ and $20 \pm 1 \mathrm{pS}(n=3)$ at positive potentials. Gating characteristics of human and rat $\mathrm{Cl}^{-}$ channels were similar (see above).

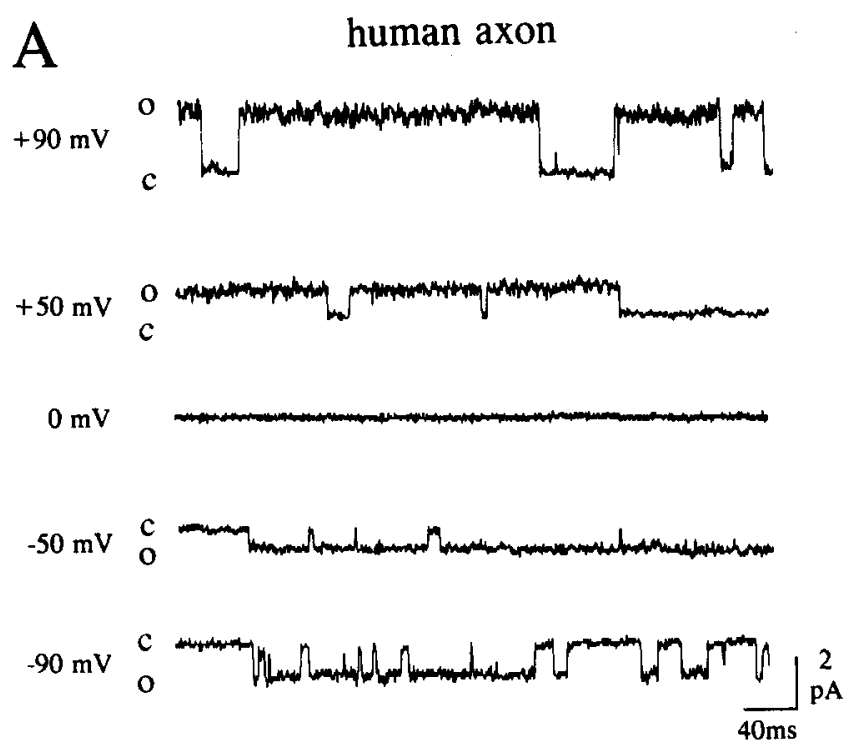

B

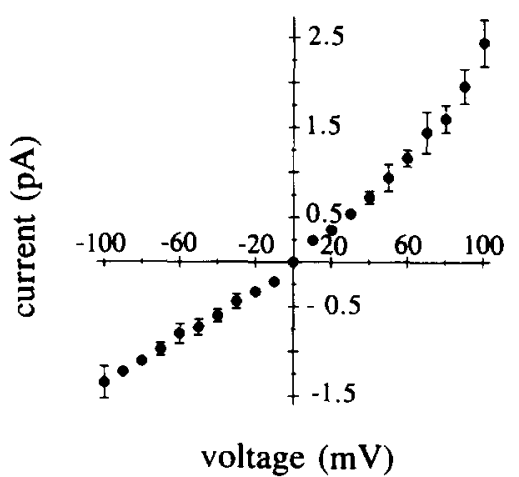

Fig. 3. A: single channel recordings of the $\mathrm{Cl}^{-}$channel from specimens of human sural nerve in symmetrical $150 \mathrm{mM} \mathrm{NaCl}$ solution (excised, inside-out configuration). Closed and open states are indicated by $\mathrm{c}$ and $\mathrm{o}$, respectively. $\mathrm{B}$ : single channel current-voltage relationship of the $\mathrm{Cl}^{-}$channel. Illustrated data are averaged (mean \pm S.D.) from 3 recordings in symmetrical $\mathrm{NaCl}$ and each current value is the average of 5 amplitude determinations from these 3 channels. At potentials from -50 to $-20 \mathrm{mV}$ the slope conductance was $14 \pm 1 \mathrm{pS}$ and at potentials from 20 to $50 \mathrm{mV}$ it was $20 \pm 1 \mathrm{pS}$. 
In contrast to sodium and potassium currents, there are very few reports of macroscopic $\mathrm{Cl}^{-}$currents in axons. Since most $\mathrm{Cl}^{-}$channels show weak voltage- and time-dependent behavior [6], they may have been dismissed as leak current. The $\mathrm{Cl}^{-}$channel found in our experiments may thus contribute to leakage current. Chiu and Schwartz [3] described a presumed $\mathrm{Cl}^{-}$current in rabbit axons, which accounts for about $5 \%$ of total current. In squid axon, Inoue [10] recorded a $\mathrm{Cl}^{-}$ current, which showed strong outward rectification and no time-dependent properties. At resting potential this current contributed $<10 \%$ of the total conductance. These macroscopic currents have many similarities with the $\mathrm{Cl}^{-}$channel described in this study.

In summary, we observed a $\mathrm{Cl}^{-}$channel on rat and human axons which is (a) open within a wide voltage range, (b) does not inactivate and (c) shows outward rectification. Functionally, this channel may contribute to the background conductance found in axons (see for discussion refs. 1,9), which stabilizes membrane potential and consequently maintains normal cell excitability.

We are grateful to Prof. Vogel and his colleagues as well as to Dr. Gordon Reid for teaching us the method of enzymatic dissociation and demyelination. We appreciate the collaboration with the Department of Neurology, Technical University of Munich (Drs. C. Franke, S. Quasthoff and W. Spittelmeister). We further thank Ms. C. Müller for technical and secretarial assistance. This work was supported by the Deutsche Forschungsgemeinschaft (SFB 220/B1).

1 Baker, M., Bostock, H., Grafe, P. and Martius, P., Function and distribution of three types of rectifying channel in rat spinal root myelinated axons, J. Physiol., 383 (1987) 45-67.

2 Blatz, A.L. and Magleby, K.L., Single chloride-selective channels active at resting membrane potentials in cultured rat skeletal muscle, Biophys. J., 47 (1985) 119-123.
3 Chiu, S.Y. and Schwarz, W., Sodium and potassium currents in acutely demyelinated internodes of rabbit sciatic nerves, J. Physiol., 391 (1987) 631-649.

4 Connors, B.W. and Ransom, B.R., Chloride conductance and extracellular potassium concentration interact to modify the excitability of rat optic nerve fibres, J. Physiol., 355 (1984) 619-633.

5 Franciolini, F. and Nonner, W., Anion and cation permeability of a chloride channel in rat hippocampal neurons, J. Gen. Physiol., 90 (1987) 453-478.

6 Franciolini, F. and Petris, A., Chloride channels of biological membranes, Biochim. Biophys. Acta, 1031 (1990) 247-259.

7 Gögelein, H., Chloride channels in epithelia, Biochim. Biophys. Acta, 947 (1988) 521-547.

8 Hamill, O.P., Marty, A., Neher, E., Sakmann, B. and Sigworth, F.J., Improved patch-clamp techniques for high-resolution current recording from cells and cell-free membrane patches, Pflügers Arch., 391 (1981) 85-100.

9 Hille, B., Ionic Channels of Excitable Membranes, Sinauer, Sunderland, MA, 1984.

10 Inoue, I., Voltage-dependent chloride conductance of the squid axon membrane and its blockade by some disulfonic stilbene derivatives, J. Gen. Physiol., 85 (1985) 519-537.

11 Jonas, P., Bräu, M.E., Hermsteiner, M. and Vogel, W., Singlechannel recording in myelinated nerve fibers reveals one type of $\mathrm{Na}$ channel but different K channels, Proc. Natl. Acad. Sci. U.S.A., 86 (1989) 7238-7242.

12 Jonas, P., Duk-Su, K., Kampe, K., Hermsteiner, M. and Vogel, W., ATP-sensitive and Ca-activated $\mathrm{K}$ channels in vertebrate axons: novel links between metabolism and excitability, Pflügers Arch., 418 (1991) 68-73.

13 Lukács, G.L. and Moczyklowski, E., A chloride channel from lobster walking leg nerves, J. Gen. Physiol., 96 (1990) 707-733.

14 Owen, D.G., Segal, M. and Barker, J.L., A Ca-dependent $\mathrm{Cl}^{-}$conductance in cultured mouse spinal neurones, Nature, 311 (1984) $567-570$.

15 Robinson, R.A. and Stokes, R.H., Electrolyte Solutions, 2nd edn., Butterworth, London, 1959.

16 Shukla, H. and Pockett, S., A chloride channel in excised patches from cultured rat hippocampal neurons, Neurosci. Lett., 112 (1990) 229-233.

17 Welsh, M.J., An apical-membrane chloride channel in human tracheal epithelium, Science, 232 (1986) 1648-1650.

18 Yamamoto, D. and Suzuki, N., Properties of single chloride channels in primary neuronal cultures of Drosophila, Biochim. Biophys. Acta, 986 (1989) 187-190. 